\title{
A unidimensional short form of the TMAS
}

\author{
ROBERT A. HICKS, JUD R. OSTLE, and ROBERT J. PELLEGRINI \\ San Jose State University, San Jose, California 95192
}

\begin{abstract}
The results of four factor-analytic studies have demonstrated that items of the TMAS load into several uncorrelated factors. To partially resolve the issue raised by these data, for the validity of the TMAS, a unidimensional short form of the TMAS was constructed.
\end{abstract}

We report here a unidimensional short form of Taylor's (1953) Manifest Anxiety Scale (TMAS). The need for a unidimensional short form of the TMAS was suggested by four factor-analytic studies of the items of the TMAS (i.e., Kahn, 1970; Notz, 1972; O'Connor, Lorr, \& Stafford, 1956; Ostle, 1974) that have all calculated several factors using the item intercorrelations of the TMAS. Specifically, O'Connor et al. (1956), using the responses of 220 college students to a 42-item version of the TMAS, calculated five independent factors. Their results have been replicated by Kahn (1970), who used the responses of 259 college students to the entire 50 items of the TMAS. More recently, Notz (1972) measured the responses of 622 college students to the 50-item TMAS and an additional 142 items that were included to help clarify the factor structure of the items of the TMAS. She identified three TMAS factors that were sufficiently well determined to be labeled. Of special interest was her finding of one broad factor that was determined by a majority of the TMAS items and was also marked by almost all the items of the "Maudsley Personality Inventory Neuroticism Scale" and the "IPAT Anxiety Scale." Essentially, this broad factor seemed to measure general tension and worry over one's ability to do tasks well, whereas the second and third TMAS factors seemed to reflect somatic concern. It should be noted that neither of these TMAS somatic concern factors was marked by items from any of other anxiety tests that she had included in her study. Finally, in an attempt to further elaborate the somatic concern factors of the TMAS, Ostle (1974), using a sample of 503 college students, factor analyzed their responses to the 50 TMAS items and an additional set of 34 items that were included to clarify the aforementioned somatic concern factors. He replicated the broad TMAS factor reported in each of the previous studies, but he failed in his attempt to further clarify the nature of the TMAS somatic concern factors.

Taken together, the results of these factor-analytic studies indicate that the TMAS measures one or more

Reprint requests should be sent to Robert A. Hicks, Department of Psychology, San Jose State University, San Jose, California 95192 . factors that may not be related to anxiety; they also seem to validate Kahn's (1970) statement "that the total score on the TMAS is a composite of dissimilar traits and hence is not meaningful" (p. 227). Here, it should be noted that it would be possible to retain the hypothesis that the total TMAS score is valid, if the TMAS factors were substantially and positively correlated. However, as both Kahn (1970) and O'Connor et al. (1956) have indicated, this is not the case. Hence, a composite obtained by adding together the items of different factors would have less internal consistency than if the factors were, or the major factor was, measured separately. Hence a good case can be made for constructing another, more nearly unidimensional form of the TMAS.

\section{METHOD}

\section{Item Selection}

The results of the studies by Kahn (1970), Notz (1970), and Ostle (1974), that is, the three aforementioned factor analyses that used all 50 TMAS items, were used to provide the basis for scale construction. In all, a sample of 1,384 college students was thus constituted. Any item, in at least two of the three studies, that loaded above .30 on the large TMAS factor, but on no other factor, was first selected. These were then ranked in order of magnitude of the first factor loadings, and the highest ranked 20 items were selected. These are given in Table 1.

The median discrimination index for each item is also given in Table 1. These values were derived from item analyses of data collected from separate samples of 72, 79, and 146 San Jose State University students. These indexes suggest that each item in the 20-item scale is making a reasonable contribution to the variance of the test as a whole.

\section{Reliability and Norms}

The test-retest reliability was determined for the 20-item scale from scores of a sample of 72 college students who were retested after a 3-month interval. The Pearsonian correlation computed from these data was .88 . The internal consistency reliability, determined in the same sample, was found to be .92 .

The norms, given on Table 2 , are based on the responses of a separate sample of 1,082 San Jose State University students. Since no significant sex difference was found (i.e., $t=.58$ ), the scores of both male and female students were pooled to form one set of norms.

\section{DISCUSSION}

A shortened form of any test is desirable for a number of reasons if it represents the original test well and is reliable. 
Table 1

Items of the Unidimensional Short Form of the TMAS and the Discrimination Index for Each Item

\begin{tabular}{l}
\hline \multicolumn{1}{c}{ Item } \\
\hline 1. I often dream about things I don't like to tell other people. \\
2. I often find myself worrying about something. \\
3. At times I lose sleep over worry. \\
4. My sleep is restless and disturbed. \\
5. At times I feel that I am going to crack up. \\
6. I feel anxious about something or someone almost all the time. \\
7. I work under a great deal of strain. \\
8. I worry quite a bit over possible troubles. \\
9. At times I have been worried beyond reason about something that really did not matter. \\
10. I am the kind of person who takes things hard. \\
11. My feelings are hurt easier than most people. \\
12. I worry over money and business. \\
13. I have nightmares every few nights. \\
14. At times I am so restless that I cannot sit in a chair for very long. \\
15. Sometimes I become so excited that I find it's hard to get to sleep. \\
16. I find it hard to keep my mind on a task or job. \\
17. Life is often a strain to me. \\
18. I am more self-conscious than most people. \\
19. I have often felt that I faced so many difficulties that I could not overcome them. \\
20. I have been afraid of things or people that I knew could not hurt me. \\
\hline
\end{tabular}

Table 2

Norms for the Unidimensional Short Form of the TMAS Based on the Scores of 1,082 San Jose State University Undergraduates

\begin{tabular}{cc}
\hline Score & Percentile Rank \\
\hline $17+$ & 99 \\
16 & 98 \\
15 & 97 \\
14 & 96 \\
13 & 93 \\
12 & 89 \\
11 & 84 \\
10 & 79 \\
9 & 72 \\
8 & 62 \\
7 & 54 \\
6 & 45 \\
5 & 34 \\
4 & 26 \\
3 & 17 \\
2 & 11 \\
1 & 6 \\
0 & 2 \\
\hline
\end{tabular}

In the present case, the shortened form is desirable for the additional reason that it provides a more nearly univocal measure than is provided by the longer form. Hence the shortened form suggested here should be of value in further research and applied work with the anxiety variable.

\section{REFERENCES}

KAHN, S. B. Dimensions of manifest anxiety and their relationship to college achievement. Journal of Consulting and Clinical Psychology, 1970, 35, 223-228.

Notz, V. R. The factor structure of tests of anxiety. Unpublished master's thesis. San Jose State University, 1972.

O’Connor, J. P., Lorr, M., \& Stafford, J. W. Some patterns of manifest anxiety. Journal of Clinical Psychology, 1956, $12,160-165$.

OstLe, J. R. A unidimensional short form of the Taylor Manifest Anxiety Scale. Unpublished master's thesis, San Jose State University, 1974.

TAYLOR, J. A. A personality scale of manifest anxiety. Journal of Abnormal and Social Psychology, 1953, 48, 285-290.

(Received for publication November 12, 1980.) 